Document downloaded from:

http://hdl.handle.net/10251/48193

This paper must be cited as:

Martí Calatayud, MC.; García Gabaldón, M.; Pérez-Herranz, V.; Sales, S.; Mestre, S. (2013). Synthesis and electrochemical behavior of ceramic cation-exchange membranes based on zirconium phosphate. Ceramics International. 39(4):4045-4054. doi:10.1016/j.ceramint.2012.10.255.

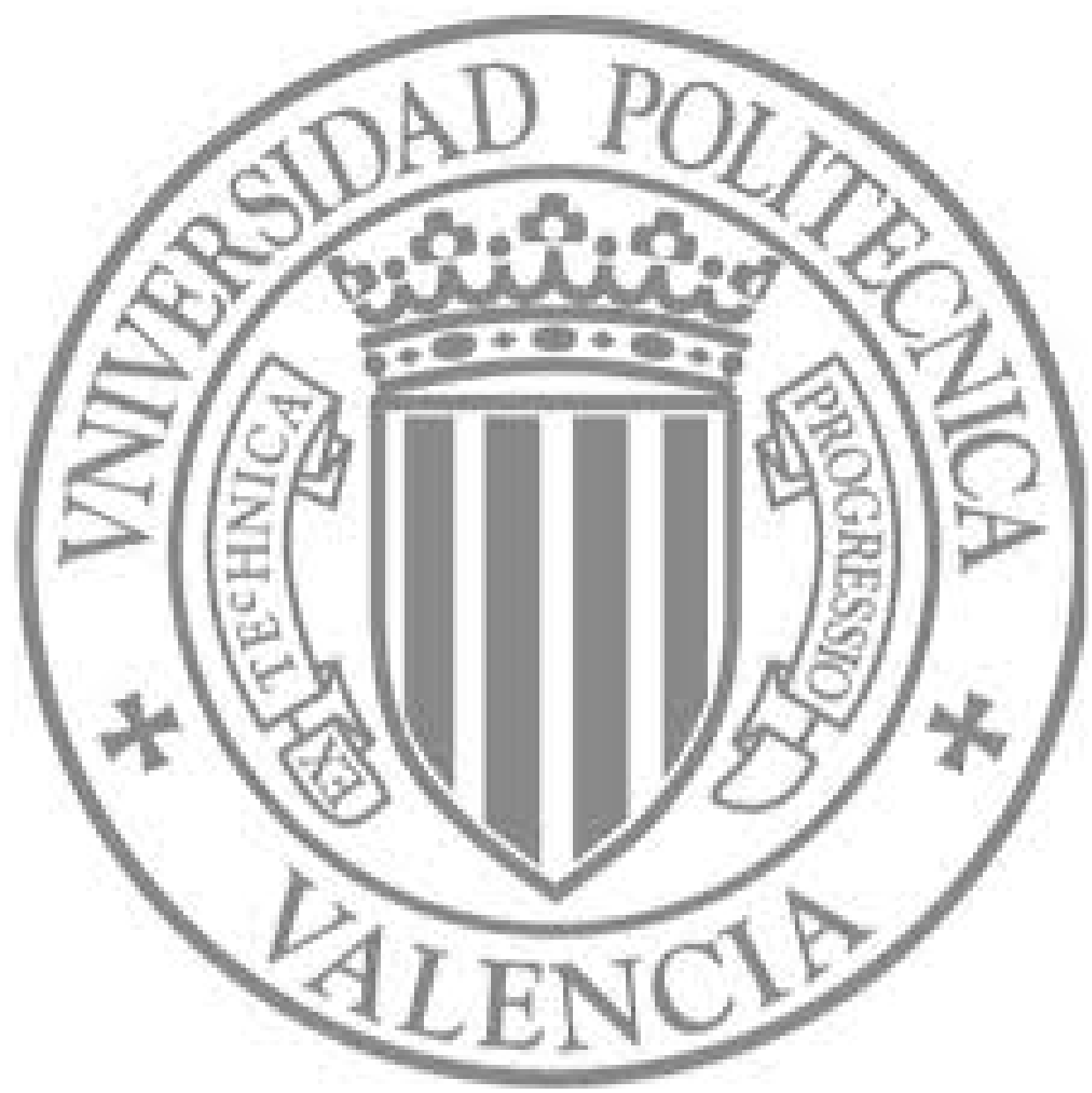

The final publication is available at

Copyright Elsevier 


\title{
Synthesis and electrochemical behaviour of ceramic cation-exchange membranes based on zirconium phosphate
}

M.C. Martí-Calatayud ${ }^{1}$, M. García-Gabaldón ${ }^{1}$, V. Pérez-Herranz ${ }^{1 *}$, S. Sales ${ }^{2}$, S. Mestre $^{2}$

${ }^{1}$ Grupo IEC, Departamento de Ingeniería Química y Nuclear, E.T.S.I.Industriales, Universitat Politècnica de València, P.O. Box 22012, E-46071, València, Spain, *Corresponding author, Fax: +34-96-3867639; Tel:+34-96-3877632;

E-mail:vperez@iqn.upv.es (V.Pérez-Herranz)),mamarc13@upvnet.upv.es (M.C. Marti-Calatayud)

${ }^{2}$ Instituto de Tecnología Cerámica, Campus Universitario Riu Sec, Av. Vicent Sos Baynat s/n, 12006, Castellón, Spain

Keywords: ceramic ion-exchange membranes, zirconium phosphate, chronopotentiometry

\begin{abstract}
Cation-exchange membranes made exclusively from ceramic materials have been synthesized by means of the impregnation of microporous ceramic supports with zirconium phosphate. Changes in the pore size distribution and total pore volume of the supports were provoked by the addition of starch as pore former in the fabrication procedure. This allowed the production of supports with increased effective electrical conductivities and with larger pores available for the zirconium phosphate deposition. An improved functionality for the exchange of cations was given to the ceramic membranes by means of their impregnation with the active particles of zirconium phosphate. The ion-exchange properties of the membranes were increased with further impregnation cycles and the resulting current-voltage curves showed a similar shape to that typical of commercial polymeric ion-exchange membranes. The production of ion-
\end{abstract}


exchange membranes with increased chemical and radiation stability will broaden their applicability for the treatment of specific industrial waste waters, which are very aggressive for the current commercial ion-exchange membranes.

\section{Introduction}

Electrodialysis (ED) has emerged as a suitable technology for the treatment of waste waters generated in industrial processes, such as metal finishing or mining activities. In contrast to other technologies, ED also allows the recovery of valuable amounts of metals for their reuse as raw materials in the industry, and the treatment of significant volumes of water without using additional chemicals and avoiding the generation of contaminant sludge [1-3]. Therefore, the application of this technology to treat specific industrial effluents could imply economical and environmental advantages. However, the durability of the ion-exchange membranes is limited when the waste solutions are very acidic, oxidizing or contain radioactive agents, thus implying the necessity of a periodic replacement of the membranes. Furthermore, ion-exchange membranes determine to a great extent the investment costs, the efficiency of the separation and the energy comsumption of electrodialytic operations, hence constituting the key components of ED cells. In the case of polymeric cation-exchange membranes (CEMs), to date, those based on a perfluorosulphonic structure are the most reliable since they own good chemical stability and have an acceptable durability. Nevertheless, their cost restricts a wider utilization of ED for the treatment of strongly oxidizing or radioactive effluents. In this sense, previous studies pointed out the use of ceramic-based membranes with ion-exchange properties as a promising alternative to polymeric membranes for specific applications due to their chemical stability and relatively low cost [4-6]. 
Different inorganic compounds with cation-exchange properties have been included in a polymeric matrix or in a ceramic support, such as barium and zirconium phosphate [711], zirconyl tungstate [12], ammonium molybdophosphate [13], or NASICON membranes based on mixed powders of sodium phosphate and zirconium silicates [1415]. In particular, acid salts of tetravalent metals like $\mathrm{Zr}$, $\mathrm{Ti}$, $\mathrm{Th}$ or $\mathrm{Ce}$ are known to have ion-exchange properties. Specifically, the $\alpha$ phase of zirconium monohydrogen phosphate $\left(\mathrm{Zr}\left(\mathrm{HPO}_{4}\right)_{2} \cdot \mathrm{H}_{2} \mathrm{O}\right)$, commonly denoted as $\mathrm{HZrP}$, has a layered structure with two protons per each $\mathrm{Zr}\left(\mathrm{PO}_{4}\right)_{2}{ }^{2-}$ anion that are oriented towards the interlayer space, which can be exchanged with other cations $[16,17]$. Thereby, composite membranes with $\alpha-H Z r P$ have been synthesized for their use in fuel cells showing properties such as reduced methanol permeability and high chemical and thermal stability [18-22]. Moreover, the ion-exchange mechanism of $\mathrm{HZrP}$ involves not only the exchange of the hydrogen ions present in the interlayer space but also of those present in the surface of $\alpha-\mathrm{HZrP}$ crystals. In this regard, a high affinity between the surface of $\alpha-\mathrm{HZrP}$ and large cations of transition elements was proven in a previous study [23]. Nevertheless, electrochemical separators should own additional characteristics apart from the ionexchange properties, such as high mechanical and chemical resistance, and a large void fraction in order to guarantee a reduced electrical resistance [24].

In the present work, CEMs obtained exclusively from ceramic materials are presented. For this purpose, porous ceramic supports were synthesized from a mixture of starch, alumina and kaolin. The cation-exchange properties of the membranes were provided by their impregnation with zirconium phosphate. The obtained membranes combine the ion-exchange properties of the active inorganic exchanger with the microporous ceramic 
structure that ensures electrical continuity in the system. Therefore, the behaviour of the membranes would be determined by their porous structure and by the chemical interactions between the active substance and the solution counter-ions. The membrane microstructure and the amount of impregnated ion exchanger have been varied as a function of the fabrication procedure. The objective of this study is to investigate the effect of the membrane porosity and pore size distribution on the membrane electrical conductivity. In addition, the influence of the number of cationic exchanger impregnation cycles on the electrochemical response is evaluated.

\section{Experimental}

\subsection{Materials and reagents}

Synthetic solutions of nickel $10^{-3}$ and $10^{-2} \mathrm{M}$ were prepared for the chronopotentiometric experiments. For this purpose, $\mathrm{NiSO}_{4} \cdot 6 \mathrm{H}_{2} \mathrm{O}(99 \%$, Panreac) and distilled water were used. $\mathrm{Ni}^{2+}$ ions were selected as the target ions since an important amount of $\mathrm{Ni}$ (II) ions is present in spent waters generated in finishing operations. The anion-exchange membrane (AEM) used for the chronopotentiometric experiments was a heterogeneous Ionics AR-204-SZRA-412 membrane (from Ionics Inc.).

\subsection{Preparation of the ceramic membranes}

The supports were synthesized from a mixture of alumina (AR12B5, Aluminium Pechiney, France), kaolin (ER, Caobar S.A., Spain) and starch (Starch from potatoes, Fluka AG, Germany) in a proportion which made the processing of the raw materials feasible by dry pressing. The composition of the initial mixture was alumina and kaolin at $50 \%$ in weight (which were selected because of their resistance in acidic media), to which varying proportions of starch were added (between $0 \%$ and $25 \%$ in weight). The 
raw materials were homogenized in a ball mill with acetone. The resulting suspension was dried under IR lamps until a water content of $4 \mathrm{~kg} \mathrm{H}_{2} \mathrm{O} / 100 \mathrm{~kg}$ dry solid was achieved. Cylindrical test specimens with a characteristic thickness of $6 \pm 0.25 \mathrm{~mm}$ were formed by uniaxial dry pressing at $400 \mathrm{~kg} \mathrm{~cm}^{-2}$. Then, the green supports were dried in an oven at $110^{\circ} \mathrm{C}$ and sintered in an electric kiln (RHF1600, Carbolite Furnaces Ltd, U.K), with a thermal cycle designed to oxidize the organic matter in less than six hours at the maximum temperature $\left(1400^{\circ} \mathrm{C}\right)$.

Zirconium phosphate was deposited in the porous network of the supports by direct precipitation. First, the ceramic supports were partially immersed for 30 minutes in a $0.5 \mathrm{M} \mathrm{ZrOCl}_{2} \cdot 8 \mathrm{H}_{2} \mathrm{O}$ solution (98\%, Sigma Aldrich $\mathrm{GmbH}$, Germany), so that only the lower surface of the supports was in contact with the liquid and the solution could be sucked into the porous network. The solution-saturated supports were immersed in $\mathrm{H}_{3} \mathrm{PO}_{4}(85 \%$, Fluka AG, Germany) for 24 hours to precipitate the zirconium phosphate inside the pores. Then, the membranes were washed with distilled water to neutral reaction and dried at $110^{\circ} \mathrm{C}$. Finally, the membranes were thermally treated at $450^{\circ} \mathrm{C}$ in order to fix the zirconium phosphate particles on the surface of the pores. The infiltration process was repeated up to five times (the number of infiltrations is denoted by $n)$. The mass of the membranes was measured after each infiltration cycle to evaluate the quantity of cation exchanger deposited. The $\lambda$ parameter, indicated in Eq. (1), is defined in order to evaluate the progress of the infiltration process in each support.

$$
\lambda=\frac{\text { mass of zirconium phosphate deposited }}{\text { mass of the support }}
$$

\subsection{Membrane characterization}

The mineralogical composition of the membranes was obtained by X-ray diffraction 
(XRD) (D8 Advance, Bruker AXS Inc, USA). Mercury intrusion porosimetry (AutoPore IV 9500 porosimeter, Micromeritics Instrument Co, USA) was used to measure the pore size distribution and the total pore volume $\left(\mathrm{T}_{\mathrm{VP}}\right)$. The morphology and composition of the membranes was analyzed in polished sections by Field Emission Gun-Scanning Electron Microscopy (FEG-SEM) (QUANTA 200F, FEI Co, USA) and Energy-dispersive X-ray spectroscopy (EDX) (Genesis 7000 SUTW, EDAX, USA).

\subsection{Determination of the ion-exchange capacity}

The ion-exchange capacity (IEC) of the impregnated membranes was determined by applying the following procedure:

1. The membranes were initially equilibrated in $1 \mathrm{M} \mathrm{HCl}$ solution during 24 hours under stirring conditions.

2. Secondly, the membranes were extracted from the solution and were rinsed several times with distilled water in order to remove any trace of acidity present at the membranes surface and inside the membrane internal voids.

3. The membranes were equilibrated in $1 \mathrm{M} \mathrm{NaCl}$ solution for 24 hours under stirring conditions in order to replace the $\mathrm{H}^{+}$ions bound to the fixed charges with $\mathrm{Na}^{+}$ions.

4. An aliquot of the equilibrating solution was extracted and titrated against $0.1 \mathrm{M}$ $\mathrm{NaOH}$ using phenolftalein as the indicator. The IEC was calculated by using Eq. (2), where $\mathrm{V}$ represents the volume of titrant added at the equivalent point, $\mathrm{M}$ refers to the molar concentration of $\mathrm{NaOH}$ and $\mathrm{w}_{\text {dry }}$ is the weight of the dry membrane [20]:

$$
I E C=\frac{V \cdot M}{w_{d r y}}
$$




\subsection{Chronopotentiometric measurements}

A schematic diagram of the experimental test rig used for the chronopotentiometric measurements can be seen in Fig. 1. The ED cell was divided in three compartments of $130 \mathrm{ml}$ of volume capacity. These compartments, which were made of PVC, possess upper apertures which allowed the installation of the reference, working and counterelectrodes. Prior to use, the membranes were equilibrated during 24 hours under stirring conditions in the solution with the same concentration as that of the solution to be used in the subsequent experiments. After the equilibrating step, the membranes (with an effective area of $8.04 \mathrm{~cm}^{2}$ ) were clamped between the compartments. During the experiments, current values were imposed between two graphite electrodes by a potentiostat/galvanostat (Autolab, PGSTAT 20), and two $\mathrm{Ag} / \mathrm{AgCl}$ reference electrodes immersed in Luggin capillaries and placed next to each side of the membrane were used to measure the voltage drop across the membrane $\left(U_{m}\right)$. All the experiments were conducted at room temperature $\left(25^{\circ} \mathrm{C}\right)$ and without stirring. The potentiostat/galvanostat was connected to a data acquisition system in order to register the measured variable.

The different synthesized ceramic membranes under study were placed between the central and the cathodic compartment whereas the AEM was installed separating the anodic and the central compartment. The AEM was employed to impede the passage of $\mathrm{H}^{+}$ions generated at the anode, minimizing their interference in the $\mathrm{U}_{\mathrm{m}}$ measurements. Under the imposition of an electric field, the positively charged ions in solution $\left(\mathrm{Ni}^{2+}\right.$ ions) are transported through the CEM. This process was measured by the reference electrodes. In the case of the AEM, anionic species such as $\mathrm{SO}_{4}{ }^{2-}$ ions are transported from the central toward the anodic compartment. 
First, a current sweep voltammetry experiment was carried out with a scan rate of 5 $\mathrm{mV} / \mathrm{s}$, which allowed the obtention of the current-voltage curve (CVC) for each membrane. Therefore, the CVCs obtained from the current sweep voltammetry experiments were used in order to select different values of current for the subsequent chronopotentiometric experiments. Chronopotentiometric tests consisted in the application of current pulses with 300 seconds of pulse duration and the registration of the $U_{m}$ values. Then, the relaxation process of the membranes was allowed during 300 additional seconds without application of current.

\section{Results and discussion}

3.1. Membrane structure and impregnation with zirconium phosphate

\subsubsection{Mineralogy and microstructure}

The synthesized supports mainly consist of mullite and corundum, with a small proportion of cristobalite. Additionally, the membranes include zirconium monohydrogen phosphate $(\mathrm{HZrP})$ and anhydrous zirconium phosphate $\left(\mathrm{ZrP}_{2} \mathrm{O}_{7}\right.$, or $\left.\mathrm{ZrP}\right)$ (Fig. 2). Therefore, the HZrP is fixed on the support during the heat treatment, but at the cost of partial dehydration. The FEG-SEM analysis indicates that the zirconium phosphate deposition does not take place equally in all the volume of the supports (Fig. 3 ), and the ion exchanger might accumulate in the pores near the surface. Despite these accumulations, a gradual enrichment of $\mathrm{Zr}$ and $\mathrm{P}$ was observed in the volume of the membranes as the number of infiltrations was increased. $\mathrm{Zr}$ or $\mathrm{P}$ were not separately identified in the support (the EDX signal of both appears practically in the same energy range of Fig. 4), but an increasing quantity of these elements was detected in the membranes, as the number of infiltration cycles grew. 


\subsubsection{Effect of the starch content}

Different proportions of starch were added to the initial alumina-kaolin mixture to modify the microstructure of the ceramic supports. As commented before and reported previously by García-Gabaldón et al. [24], when the green shaped supports are submitted to the sintering cycle, starch particles burn and generate pores of different size. Besides this, since the impregnation of the ceramic supports occurs in the walls of the porous network, the amount of zirconium phosphate deposited in each impregnation cycle is supposed to depend upon the porosity of the support.

The obtained results confirm a direct relationship between the percentage of starch in the raw materials mixture and the $\mathrm{T}_{\mathrm{VP}}$ of both supports and membranes. However, the evolution of $\lambda$ for the membranes with $n=1$ as a function of the starch content is quite different, since an important increase occurrs for a starch content of $20 \%$. This behaviour can be interpreted considering the evolution of the pore size distribution of the ceramic supports (Fig.5). The pores generated by the starch addition are not interconnected when the starch percentage added is low (the bimodal pore size distribution of the support without starch is maintained). Therefore, the zirconium phosphate precursors can only access through the very narrow channels generated by the alumina-kaolin mixture and $\lambda$ remains low. However, when the starch percentage exceeds $20 \%$, the pores generated are already interconnected and a trimodal pore size distribution is observed, which significantly improves the access of zirconium phosphate precursors. This fact results in higher values of $\lambda$.

\subsubsection{Effect of the number of impregnation cycles}

The supports obtained for a starch content of $20 \%$ were selected to be submitted to 
additional zirconium phosphate impregnation cycles. These supports have a high value of $\mathrm{T}_{\mathrm{VP}}$, together with an acceptable mechanical strength.

The successive impregnation cycles lead to an increased quantity of the ion exchanger deposited, and consequently, to decreasing values of $\mathrm{T}_{\mathrm{VP}}$ (see Fig. 6). Specifically, $\lambda$ showed a slightly parabolic upward trend and $\mathrm{T}_{\mathrm{VP}}$ showed an unexpected downward sigmoidal trend. The evolution of $\mathrm{T}_{\mathrm{VP}}$ indicates that the deposition of zirconium phosphate does not take place homogeneously throughout the porous network. This fact was already observed in the FEG-SEM image of Fig. 3-b, and is confirmed by the pore size distribution of the membranes (Fig. 7). By increasing the number of cycles, the fraction of porosity corresponding to larger pores decreases (pore diameters around 3 and $5 \mu \mathrm{m}$ ), whereas the fraction of porosity corresponding to pores of smaller diameter displays a more complicated evolution (pore diameters around 0.1 and $0.4 \mu \mathrm{m}$ ). Specifically, the fraction of porosity corresponding to $d_{p}=0.4 \mu \mathrm{m}$ shows a minimum for $\mathrm{n}=3$, while the fraction of porosity with smaller diameter displays a downward trend, but with two significant tails of lower diameters for $n=3$ and $n=4$. This behaviour may indicate that zirconium phosphate can be deposited forming aggregates, both compact and porous. The former would be able to block the pores and the latter would include the pores below $0.1 \mu \mathrm{m}$.

The increase in the amount of deposited zirconium phosphate and associated changes in the pore size distribution affects the IEC values of the membranes, as presented in Fig. 8. This property is significantly improved when changing from $n=2$ to $n=3$. A maximum in IEC is observed for $n=3$ and IEC values remain above $0.05 \mathrm{meq} / \mathrm{g}$ for higher values of $n$. However, the decrease of IEC observed for $n>3$ seems to indicate 
that the higher values of $\lambda$ obtained for these membranes do not correspond to an effective improvement of the IEC, but contributes to the blockage of pores without increasing the available fixed charges for the ion exchange. This phenomenon is in congruence with the evolution of $\mathrm{T}_{\mathrm{VP}}$ observed in Fig. 6.

\subsection{Membrane electrochemical behavior}

\subsubsection{Effect of the starch content}

Once the structural characterization of the ceramic membranes was accomplished, their electrochemical behaviour was also evaluated. For this purpose, chronopotentiograms and CVCs were obtained for each manufactured membrane. The CVC of a separator used in an electrochemical reactor represents the relationship between the applied current density and $U_{m}$ [25]. In the case of commercial polymeric ion-exchange membranes, CVCs are composed of three regions, each one describing distinct types of behaviour of the membranes and appearing at different current regimes [26-29]. In the low range of currents, a straight dependence between the current density and the membrane voltage drop indicates a quasi-ohmic behaviour of the membranes. In this region, ions are transported in the solution layers next to the membrane mainly by means of migration and diffusion. Since ion-exchange membranes are selective to either positively or negatively charged ions depending on the sign of their fixed charges, counter-ions are preferentially transported through the membranes. Consequently, as the current density increases, the concentration of counter-ions decreases in the vicinity of the membrane [30]. When the limiting current density $\left(\mathrm{i}_{\text {lim }}\right)$ is reached, the counter-ion concentration at the membrane surface in its depleting side tends to zero. Accordingly, the current is set under diffusion control and the resistance of the diffusion layers increases, thus resulting in high increases in $U_{m}$ for very little increments in the applied 
current. At this point, the second domain is achieved and a plateau is formed in the CVC. At applied currents higher than the limiting one, ionic transfer through the membrane is again enhanced due to the contribution of other transport mechanisms such as electroconvection or to the generation of new ionic species [31], thus leading to the third region of the CVC. In contrast to the behaviour offered by commercial ionexchange membranes, ceramic separators evaluated in previous studies have been characterised by a unique zone in their respective CVCs corresponding to a linear relationship between applied current and membrane voltage drop [6,24,32,33]. Therefore, in these cases a quasi-ohmic behaviour describes the transport of ions through the separators and concentration polarization effects are neglected [32].

Fig. 9 shows different CVCs obtained with $10^{-3}$ and $10^{-2} \mathrm{M} \mathrm{NiSO}_{4}$ solutions for various manufactured ceramic membranes resulting from varying the starch content. Generally, a straight dependence between the current passed through the membranes and $U_{m}$ is observed. This straight evolution reveals a quasi-ohmic behaviour of the ceramic membranes for all the range of applied currents, which resembles that offered by ceramic separators and differs from that of commercial polymeric ion-exchange membranes. However, a very slight and gradual change of slope at high current density values can be detected in Fig. 9, especially in the case of $10^{-3} \mathrm{M} \mathrm{NiSO}_{4}$ solutions for membranes with $n=1$ and starch content values between $10 \%$ and $20 \%$. Despite the fact that the manufactured ceramic membranes show a prevailing quasi-ohmic behaviour, the slight change of slope of the CVC indicates a small increase of the membrane resistance for high values of current. In this regard, it should be noted that $\mathrm{U}_{\mathrm{m}}$ includes not only the ohmic voltage drop through the membrane, but also the voltage drop due to concentration polarization effects taking place at the membrane- 
solution interfaces as a consequence of their ion-exchange properties.

The approximately straight evolution of the current passed through the membrane with $\mathrm{U}_{\mathrm{m}}$ is evidence of the absence of intensive concentration polarization effects. Hence, the membrane electrical resistance $\left(\mathrm{R}_{\mathrm{m}}\right)$ can be calculated from the inverse of the slope of each curve. It is possible to obtain the effective electrical conductivity of the porous membranes $\left(\kappa_{\text {eff }}\right)$ from the calculated values of $\mathrm{R}_{\mathrm{m}}$, the effective membrane area $\left(\mathrm{A}_{\mathrm{m}}\right)$ and their thickness $(e)$ by means of using the following expression [25]:

$$
\kappa_{\text {eff }}=\frac{e}{R_{m} \cdot A_{m}}
$$

The effective electrical conductivity values are represented in Fig. 10 for each membrane with $n=1$ as a function of their $T_{V P}$ values. The ceramic support without impregnation offers higher $\kappa_{\text {eff }}$ values than the supports without starch addition and $\mathrm{n}=$ 1 for the two electrolyte concentrations. As $T_{V P}$ increases up to a value of $0.285 \mathrm{~cm}^{3} \cdot \mathrm{g}^{-1}$ (which corresponds to a starch content of $10 \%$ ), $\kappa_{\text {eff }}$ values decrease notably. On the contrary, for further increases in the starch content the membrane conductivity increases together with the increase in the $\mathrm{T}_{\mathrm{VP}}$ values. Considering that the increased porosity leads to higher volumes of solution within the pores, this behaviour can be interpreted assuming that the increase in $\mathrm{T}_{\mathrm{VP}}$ generated by the starch does not entail a reduction in $\mathrm{R}_{\mathrm{m}}$ until the interconnection of the bigger pores begins to be significant (change of pore size distribution from bimodal to trimodal, see Fig.5). Moreover, the maximum pore diameter is less than one micron for the supports obtained with starch contents $\leq 10 \%$, and this is the pore range in which zirconium phosphate is preferably deposited. This turns into a reduction of the hydraulic permeability and explains the decrease in $\kappa_{\text {eff }}$ values. It should be pointed out that the minimum in $\kappa_{\text {eff }}$ showed by the membranes with 
a starch content of $10 \%$ is in agreement with a previous study carried out with aluminakaolin porous separators by García-Gabaldón et al. ${ }^{24}$, in which the decrease of $\kappa_{\text {eff }}$ was attributed to the narrower pore size distribution of those supports.

\subsubsection{Effect of the number of impregnation cycles}

In the previous section, the membrane with a starch content of $20 \%$ and $n=1$ showed a combination of high electrical conductivity and noticeable ion-exchange properties. For this reason, this membrane was selected for the study of the effect of the number of zirconium phosphate impregnation cycles on the membrane chronopotentiometric response. Moreover, this support allows the application of a high number of impregnation cycles due to the great pore volume available inside its structure. In the low current range, a quasi-ohmic behaviour describes the relationship between current density and membrane voltage drop for the membranes with $n>1$. The slope of the resulting CVCs decreases with the number of impregnation cycles whereas it increases with the electrolyte concentration, as occurred for the membranes with $n=1$ (Fig. 9). The values of $\kappa_{\text {eff }}$ were calculated from the CVCs, and are plotted in Fig. 11 as a function of the number of impregnation cycles for the two electrolyte concentrations tested. A general decrease of $\kappa_{\text {eff }}$ with the number of impregnations confirms the important role of $\mathrm{T}_{\mathrm{VP}}$ on the ohmic conductance of the membranes. As a rule, the more zirconium phosphate impregnated the lower values of $\mathrm{T}_{\mathrm{VP}}$, and consequently the lower resulting $\kappa_{\text {eff }}$ values. It seems that the ions filling the membrane pores are the main responsible for the ohmic conductance of the membranes. In this respect, $\mathrm{T}_{\mathrm{VP}}$ values lower than $0.3 \mathrm{~cm}^{3} / \mathrm{g}$, which correspond with membranes having four or more impregnation steps, lead to an acute decrease in the membrane conductivity. This is directly related to the reduction of the fraction of pores with a diameter over $1 \mu \mathrm{m}$. 
Moreover, the difference between the $\kappa_{\text {eff }}$ values obtained for solutions of nickel sulphate $10^{-3}$ and $10^{-2} \mathrm{M}$ are broader for membranes with less than four impregnation steps, being nearly two-fold in the case of $10^{-2} \mathrm{M} \mathrm{NiSO}_{4}$ solutions. Nevertheless, for those membranes with a reduced $\mathrm{T}_{\mathrm{VP}}$ values, the volume of electrolyte filling the pores is clearly diminished and the difference between $\kappa_{\text {eff }}$ values for both concentrations too, hence denoting the importance of the pores with large diameter in order to produce membranes with high $\kappa_{\text {eff }}$ values.

Regarding the influence of the number of impregnation cycles on the chronopotentiometric response, the results obtained for the porous supports without zirconium phosphate impregnation correspond to an evolution of $U_{m}$ with time almost constant and without any delay in relation to the applied current pulse. Hence, in analogy with previous studies about ceramic supports [6,24,32,33], important concentration polarization phenomena do not take place in this case. In contrast, the shape of the chronopotentiograms of membranes obtained after various impregnation cycles (Fig. 12) is quite similar to that seen in commercial ion-exchange membranes $[3,25,34]$. The contribution of the ohmic overpotential to $U_{m}$ is reached immediately after the current is switched on. However, during the imposition of the current pulse an important increase of the membrane voltage drop takes place for currents surpassing $\mathrm{i}_{\mathrm{lim}}$, which is a sign of the decrease of the ion concentration occurring at the anodic side of the membrane. The difference between the final value of $U_{m}$ registered at the end of the current pulse and the ohmic overpotential is known as the interfacial transfer overvoltage $\left(\eta_{t}\right)$, and is attributed to the ion-exchange properties brought by HZrP, which involves an increased transfer through the membranes and the emergence of concentration polarization [35]. Moreover, an increase in the applied current leads to 
greater values of $\eta_{t}$, since the reduction of nickel ion concentration next to the membrane in the depleting compartment is greater at high current density values. The emergence of an important interfacial transfer overvoltage occurs for values of $n \geq 3$ and indicates an increased ion-exchange character of the membranes as a consequence of their impregnation with $\mathrm{HZrP}$, which is in agreement with the IEC results above presented. However, $U_{m}$ grows gradually without a sharp increase in the chronopotentiogram. Conversely, with polymeric ion-exchange membranes the increase in $U_{m}$ when the $i_{\text {lim }}$ is reached occurs more sharply [3]. This sharp increase is usually considered to occur when the concentration of ions at the depleting side of the membrane reaches zero. This difference could be regarded as a consequence of the heterogeneity of the ceramic membranes and due to the concurrence of two different processes taking part in the ionic transfer through the manufactured ceramic ionexchange membranes. On the one hand, ions are transferred through the ceramic membranes via the ion-exchange mechanism taking place between cations and the fixed charges of the membrane. In addition, there is an important contribution of the internal volume of the pores to the conductance of the membranes. This assumption is in agreement with the findings of Alberti et al., who pointed out that membranes constituted of acid salts of tetravalent metals, though being heterogeneous, behave as homogeneous porous membranes [36]. Finally, it has been noticed that the contribution of the interfacial transfer overvoltage to the total membrane voltage drop becomes more important for membranes with three or more impregnation cycles.

In addition to the information given by chronopotentiometry, the final values of $U_{m}$ registered in the chronopotentiograms can be plotted as a function of the applied current. Accordingly, CVCs analogous to those obtained by current sweep voltammetry 
can be obtained, being several of these curves presented in Fig. 13. A kind of second region appears at high values of current density as a consequence of a change in the slope, which is quite similar to the plateau zone appearing in the CVCs of commercial ion-exchange membranes. In concordance with the chronopotentiograms shown previously, no important concentration polarization occurs in the case of membranes without zirconium phosphate impregnation, whereas the plateau region appears in the case of the impregnated membranes as a consequence of the contribution of $\eta_{t}$ to the total membrane voltage drop. The change of slope is much more pronounced in the case of $10^{-3} \mathrm{M} \mathrm{NiSO}_{4}$ solutions as a consequence of the more intense concentration polarization phenomena occurring with weak solutions. The manifestation of a second region in the manufactured membranes confirms their ion-exchange characteristics and opens the possibility of obtaining low cost ion-conducting membranes exclusively made from ceramic materials which could resist the oxidizing and acidic nature of specific industrial effluents. For this purpose, the uniformity within the pore size and the need for a determined pore diameter are considered to be crucial requirements in order to accomplish an effective inclusion of guest crystals in porous host materials [37]. In the present case, it has been proven that the inclusion of zirconium phosphate inside the structure of microporous membranes impart ion-exchange properties to ceramic membranes, which could broaden the application of ED to the treatment of contaminant and hazardous waste waters.

The synthesized membranes could be used, for example, to treat spent chromium baths used in the metal finishing industry, which are very oxidizing [1]. These baths become spent when the concentration of metallic impurities coming from the dissolution of the treated pieces reaches a certain level and the current efficiency for the chromium 
deposition decreases. In practice, a two-compartment ED cell with the ceramic CEMs installed as a separator could be used to remove the cationic impurities. The membrane, placed between the cathodic and the anodic compartment, would act as a selective barrier. The anionic species would be retained in the anolyte, while the removal of cationic impurities, such as $\mathrm{Ni}^{2+}$ ions, would take place by means of their transport through the membrane. Simultaneously to the removal of cationic impurities, the regeneration of chromic acid would occur at the anodic compartment where $\mathrm{H}^{+}$ions are produced. Other potential applications of the produced membranes include the zinc recovery [38], or the sodium removal from nuclear waste in order to reduce the weight and disposal cost of the waste [39].

\section{Conclusions}

The manufacture of cation-exchange membranes from inexpensive ceramic materials has been achieved by means of incorporating zirconium phosphate in a porous support derived from a mixture of alumina, kaolin and starch. The starch added to the initial raw materials promoted significant changes in the pore size distribution and in the $\mathrm{T}_{\mathrm{VP}}$ values of the different supports. The addition of starch contents higher than $15 \% \mathrm{wt}$. promoted a trimodal pore size distribution with characteristic pore diameters higher than $1 \mu \mathrm{m}$, which implied increased values of $\kappa_{\text {eff }}$ and $\lambda$. Increasing cycles of impregnation with zirconium phosphate lead to a higher deposition of $\mathrm{HZrP}$ in the microporous structure, which was proven in the mineralogical characterization of the membranes. This caused a decrease in the $\mathrm{T}_{\mathrm{VP}}$ values due to the blockage of pores and consequently also in the $\kappa_{\text {eff }}$ values. However, increasing cycles of impregnation with zirconium phosphate promote the cation-exchange properties of the membranes. The electrochemical behaviour of the impregnated membranes resembles the response of 
commercial polymeric cation-exchange membranes and represents an important preliminary advance for broadening the application of ED to specific applications in which an improved chemical stability of the ion-exchange membranes is required.

\section{Acknowledgements}

Manuel-César Martí-Calatayud wants to express his gratitude to Universitat Politècnica de València for a postgraduate grant (Ref. 2010-12). S. Sales would like to express her gratitude to Ministerio de Ciencia e Investigación (Spain) for a postgraduate grant (AP2009-4409). This work was supported by Ministerio de Ciencia e Innovación (Spain) with the project numbers CTQ2008-06750-C02-01/PPQ and CTQ2008-06750C02-02/PPQ.

\section{References}

[1] S.S. Chen, C.W. Li, H.D. Hsu, P.C. Lee, Y.M. Chang, C.H. Yang, Concentration and purification of chromate from electroplating wastewater by two-stage electrodialysis processes, J. Hazard. Mater. 161 (2009) 1075-1080.

[2] C. Korzenowski, M.A.S. Rodrigues, L. Bresciani, A.M. Bernardes, J.Z. Ferreira, Purification of spent chromium bath by membrane electrolysis, J. Hazard. Mater. 152 (2008) 960-967.

[3] M.C. Martí-Calatayud, M. García-Gabaldón, V.Pérez-Herranz, E. Ortega, Determination of transport properties of $\mathrm{Ni}(\mathrm{II})$ through a Nafion cation-exchange membrane in chromic acid solutions, J. Membr. Sci. 379 (2011) 449-458. 
[4] Y.S. Dzyazko, A. Mahmoud, F. Lapicque, V.N. Belyakov, Cr(VI) transport through ceramic ion-exchange membranes for treatment of industrial wastewaters, J. Appl. Electrochem. 37 (2007) 209-217.

[5] Y. Sui, X. Fu, R. Zeng, X. Ma, Preparation, characterization and application of a new type of ion exchanger and solid acid zirconium sulfonated oligopolystyrenylphosphonate-phosphate supported on $\mathrm{ZrO}$, J. Mol. Catal. A: Chem., 217 (2004) 133-138.

[6] V V.M. Linkov, V.N. Belyakov, Novel ceramic membranes for electrodialysis, Sep. Purif. Technol. 25 (2001) 57-63.

[7] R. Labayru, D.A. White, Transport of cations across inorganic membranes by electrodialysis in an electric cell, Trans IChemE, 69 (1991) 30-34.

[8] R. Labayru, E. Andalaft, Use of inorganic membranes in electrodialysis, Russ. J. Electrochem. 30 (1994) 856-858.

[9] R. Labayru, E. Andalaft, C. Albornoz, M. Correa, P. Loyola, H.S. Diaz, Properties of dynamic membranes deposited inside a ceramic base, Russ. J. Electrochem. 34 (1998) 209-211.

[10] B. Pan, B. Pan, X. Chen, W. Zhang, X. Zhang, Q. Zhang, Q. Zhang, J. Chen, Preparation and preliminary assessment of polymer-supported zirconium phosphate for selective lead removal from contaminated water, Water Res. 40 (2006) 29382946.

[11] C.A. Borgo, Y. Gushikem, Zirconium phosphate dispersed on a cellulose fiber surface: preparation, characterization, and selective adsorption of $\mathrm{Li}^{+}, \mathrm{Na}^{+}$, and $\mathrm{K}^{+}$ from aqueous solution, J. Colloid Interface Sci. 246 (2002) 343-347. 
[12] E.E. Zaki, M.S. Gasser, H.F. Aly, Separation of cesium from intermediate level waste solutions using zirconyl tungstate ceramic-supported membranes, J. Radioanal. Nucl. Chem. 246 (2000) 361-367.

[13] A.G. Kotvitskyy, T.V. Maltseva, V.N. Belyakov, Selective removal of $\mathrm{Cs}^{+}$ions by means of electro-deionisation, Sep. Purif. Technol. 41 (2005) 329-334.

[14] F. Girard, R. Izquierdo, E. Quenneville, S.T. Bah, M. Paleologou, M. Meunier, D. Ivanov, A. Yelon, Evaluation of a ceramic-polymer composite cation-selective membrane for sodium salt splitting, J. Electrochem. Soc., 146 (1999) 2919-2924.

[15] G.W. Hollenberg, D.E. Kurath, K.P. Brooks, Ceramic membranes for separation of sodium, Electrochem. Glass Ceram. 92 (1999) 245-263.

[16] A. Clearfield, W.L. Duax, A.S. Medina, G.D. Smith, J.R. Thomas, On the mechanism of ion exchange in crystalline zirconium phosphates, J. Phys. Chem. 73 (1969) 3424-3430.

[17] A. Clearfield, Role of ion exchange in solid-state chemistry, Chem. Rev. 88 (1988) 125-148.

[18] M. Helen, B. Viswanathan, S.S. Murthy, Synthesis and characterization of composite membranes based on $\alpha$-zirconium phosphate and silicotungstic acid, J. Membr. Sci. 292 (2007) 98-105.

[19] P. Costamagna, C. Yang, A.B. Bocarsly, S. Srinivasan, Nafion ${ }^{\circledR}$ 115/zirconium phosphate composite membranes for operation of PEMFCs above $100{ }^{\circ} \mathrm{C}$, Electrochim. Acta, 47 (2002) 1023-1033.

[20] B.P. Tripathi, V.K. Shahi, SPEEK-zirconium hydrogen phosphate composite membranes with low methanol permeability prepared by electro-migration and in situ precipitation, J. Colloid Interface Sci. 316 (2007) 612-621. 
[21] M. Casciola, G. Bagnasco, A. Donnadio, L. Micoli, M. Pica, M. Sganappa, M. Turco, Conductivity and methanol permeability of Nafion-Zirconium phosphate composite membranes containing high aspect ratio filler particles, Fuell Cells, 4 (2009) 394-400.

[22] M.L. Hill, Y.S. Kim, B.R. Einsla, J.E. McGrath, Zirconium hydrogen phosphate/disulfonated poly(arylene ether sulfone) copolymer composite membranes for proton exchange membrane fuel cells, J. Membr. Sci. 283 (2006) 102-108.

[23] G. Alberti, M.G. Bernasconi, M. Casciola, U. Costantino, Ion exchange of some divalent and trivalent cations on the surface of zirconium acid phosphate microcrystals, J. Chromatogr. A 160 (1978) 109-115.

[24] M. García-Gabaldón, V. Pérez-Herranz, E. Sánchez, S. Mestre, Effect of porosity on the effective electrical conductivity of different ceramic membranes used as separators in eletrochemical reactors, J. Membr. Sci. 280 (2006) 536-544.

[25] P. Dlugolecki, B. Anet, S.J. Metz, K. Nijmeijer, M. Wessling, Transport limitations in ion exchange membranes at low salt concentrations, J. Membr. Sci. $346(2010)$ 163-171.

[26] V. M. Barragán, C. Bauzá, Current-voltage curves for ion-exchange membranes: a method for determining the limiting current density, J. Colloid Interface Sci. 205 (1998) 365-373.

[27] I. Rubinstein, B. Zaltzman, Electro-osmotically induced convection at a permselective membrane, Phys. Rev. E 62 (2000) 2238-2250.

[28] J.J. Krol, M. Wessling, H. Strathmann, Concentration polarization with monopolar ion exchange membranes: current-voltage curves and water dissociation, J. Membr. Sci. 162 (1999) 145-154. 
[29] C. Klaysom, R. Marschall, S.-H. Moon, B. P. Ladewig, G. Q. M. Lu, L. Wang, Preparation of porous composite ion-exchange membranes for desalination applicatioon, Journal of Materials Chemistry, 2011, 21, 7401.

[30] V.V. Nikonenko, N.D. Pismenskaya, E.I. Belova, P. Sistat, P. Huguet, G. Pourcelly, C. Larchet, Intensive current transfer in membrane systems: Modelling, mechanisms and application in electrodialysis, Adv. Colloid Interface Sci. 160 (2010) 101-123.

[31] M. C. Martí-Calatayud, M. García-Gabaldón, V. Pérez-Herranz, Study of the effects of the applied current regime and the concentration of chromic acid on the transport of $\mathrm{Ni}^{2+}$ ions through Nafion 117 membranes, J. Membr. Sci., 392-393 (2012) 137-149.

[32] M. García-Gabaldón, V. Pérez-Herranz, E. Sánchez, S. Mestre, Effect of tin concentration on the electrical properties of ceramic membranes used as separators in electrochemical reactors, J. Membr. Sci. 323 (2008) 213-220.

[33] K. Singh, A. Singh, Membrane potential and solute separation studies on zirconium phosphate membranes, J. Membr. Sci. 82 (1993) 141-147.

[34] J. Balster, M.H. Yildirim, D.F. Stamatialis, R. Ibanez, R.G.H. Lammertink, V. Jordan, M. Wessling, Morphology and microtopology of cation-exchange polymers and the origin of the overlimiting current, J. Phys. Chem. B, 111 (2007) 2152-2165.

[35] M. Taky, G. Pourcelly, F. Lebon, C. Gavach, Polarization phenomena at the interfaces between an electrolyte solution and an ion exchange membrane: Part I. Ion transfer with a cation exchange membrane, J. Electroanal. Chem. 336 (1992) 171194. 
[36] G. Alberti, M. Casciola, U. Costantino, Inorganic ion-exchange membranes made of acid salts of tetravalent metals. A short review, J. Membr. Sci. 16 (1983) 137-149.

[37] M.E. Davis, Ordered porous materials for emerging applications, Nature, 417 (2002) 813-821.

[38] F.D.R. Amado, L.F. Rodrigues, M.A.S. Rodrigues, A.M. Bernardes, J.Z. Ferreira, C.A. Ferreira, Development of polyurethane/polyaniline membranes for zinc recovery through electrodialysis, Desalination 186 (2005) 199-206.

[39] S. Balagopal, T. Landro, S. Zecevic, D. Sutija, S. Elangovan, A. Khandkar, Selective sodium removal from aqueous waste streams with NaSICON ceramics, Sep. Purif. Technol. 15 (1999) 231-237. 


\section{List of figures}

Fig. 1. Experimental setup used for the chronopotentiometric experiments.

Fig. 2. Diffractograms of the ceramic support and the membrane obtained after five infiltration cycles.

Fig. 3. FEG-SEM images of polished sections. (a) ceramic support obtained from a mixture with $20 \%$ of starch. (b) area near the surface of a membrane obtained from the same support, after five infiltration cycles.

Fig. 4. EDX spectra of the central areas of the support (20\% of starch), and membranes obtained with three and five infiltration cycles.

Fig. 5. Differential pore size distributions of the supports obtained from mixtures with different starch contents.

Fig. 6. Effect of the number of infiltration cycles on the total pore volume and $\lambda$ values of the membranes.

Fig. 7. Effect of the number of impregnation cycles on the differential pore size distribution of the ceramic membranes.

Fig. 8. IEC as a function of the number of impregnation cycles, $n$.

Fig. 9. CVCs obtained for membranes with varying starch contents in $\mathrm{NiSO}_{4}$ solutions.

Fig. 10. Values of $\kappa_{\text {eff }}$ for $10^{-3}$ and $10^{-2} \mathrm{M} \mathrm{NiSO}_{4}$ solutions as a function of the total pore volume of the membranes resulting from different starch contents in their fabrication.

Fig. 11. Values of $\kappa_{\text {eff }}$ for $10^{-3}$ and $10^{-2} \mathrm{M} \mathrm{NiSO}_{4}$ solutions as a function of the number of impregnation steps. 
Fig. 12. Chronopotentiometric curves obtained for $10^{-3} \mathrm{M} \mathrm{NiSO}_{4}$ solutions with the CEM resulting from an initial matrix with $20 \%$ starch content and three zirconium phosphate impregnation steps.

Fig. 13. CVCs obtained from the chronopotentiograms with $10^{-3} \mathrm{M} \mathrm{NiSO}_{4}$ solutions for membranes with varying number of zirconium phosphate impregnation cycles. 


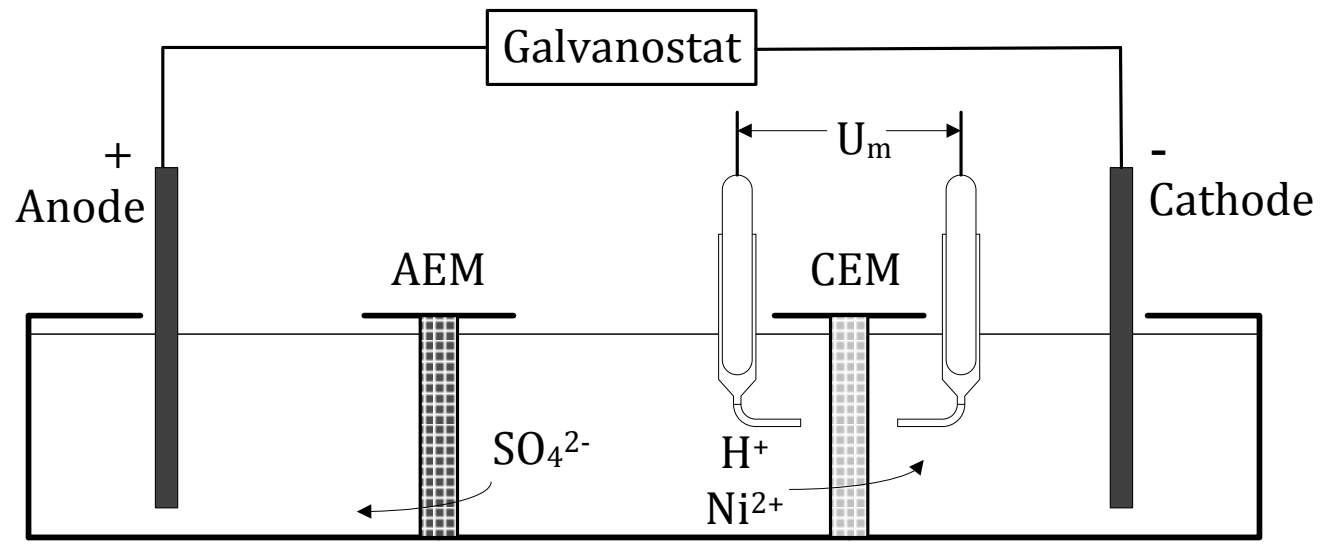

Fig. 1 Experimental setup used for the chronopotentiometric experiments. 


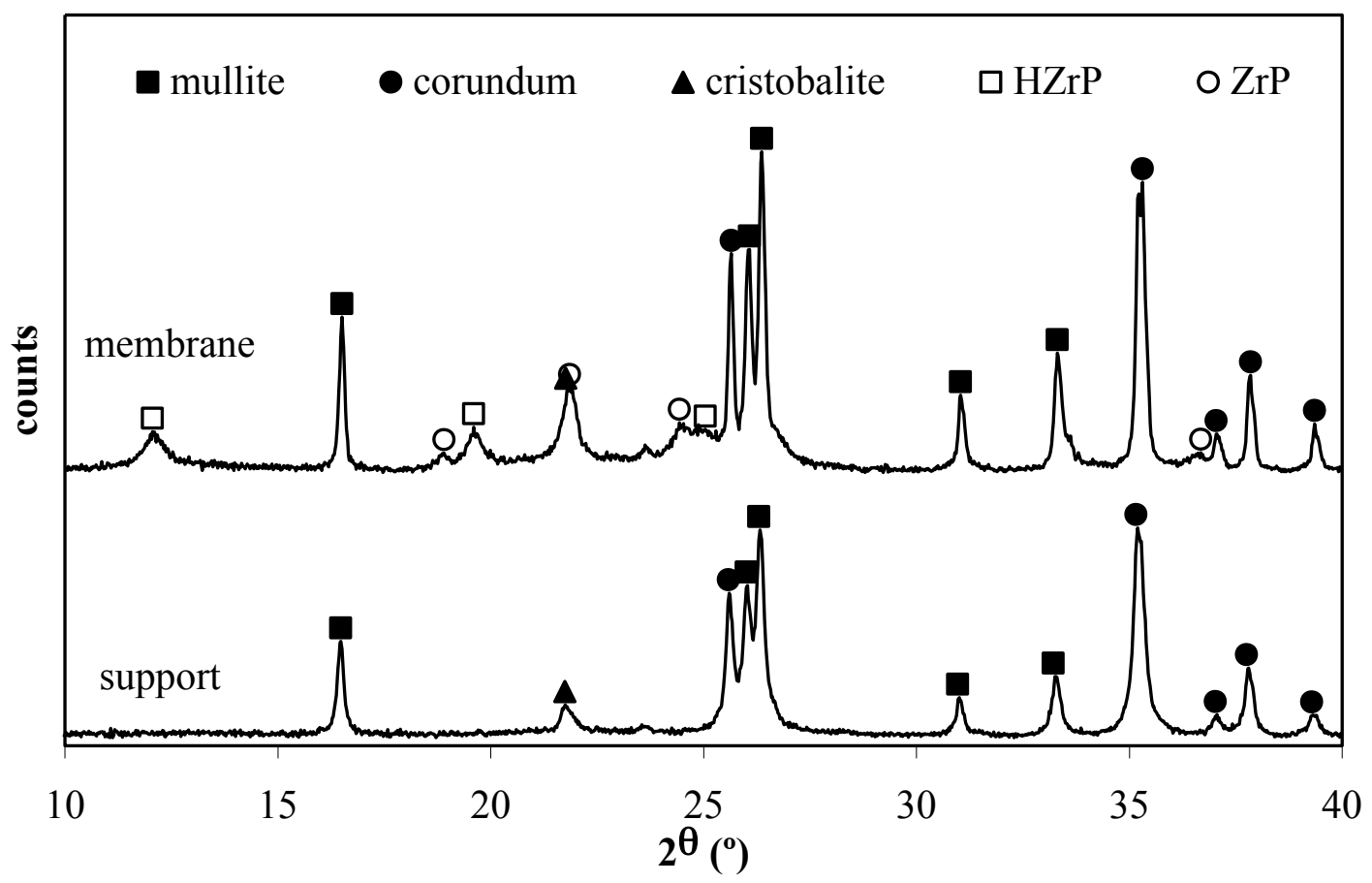

Fig. 2 Diffractograms of the ceramic support and the membrane obtained after five infiltration cycles. 


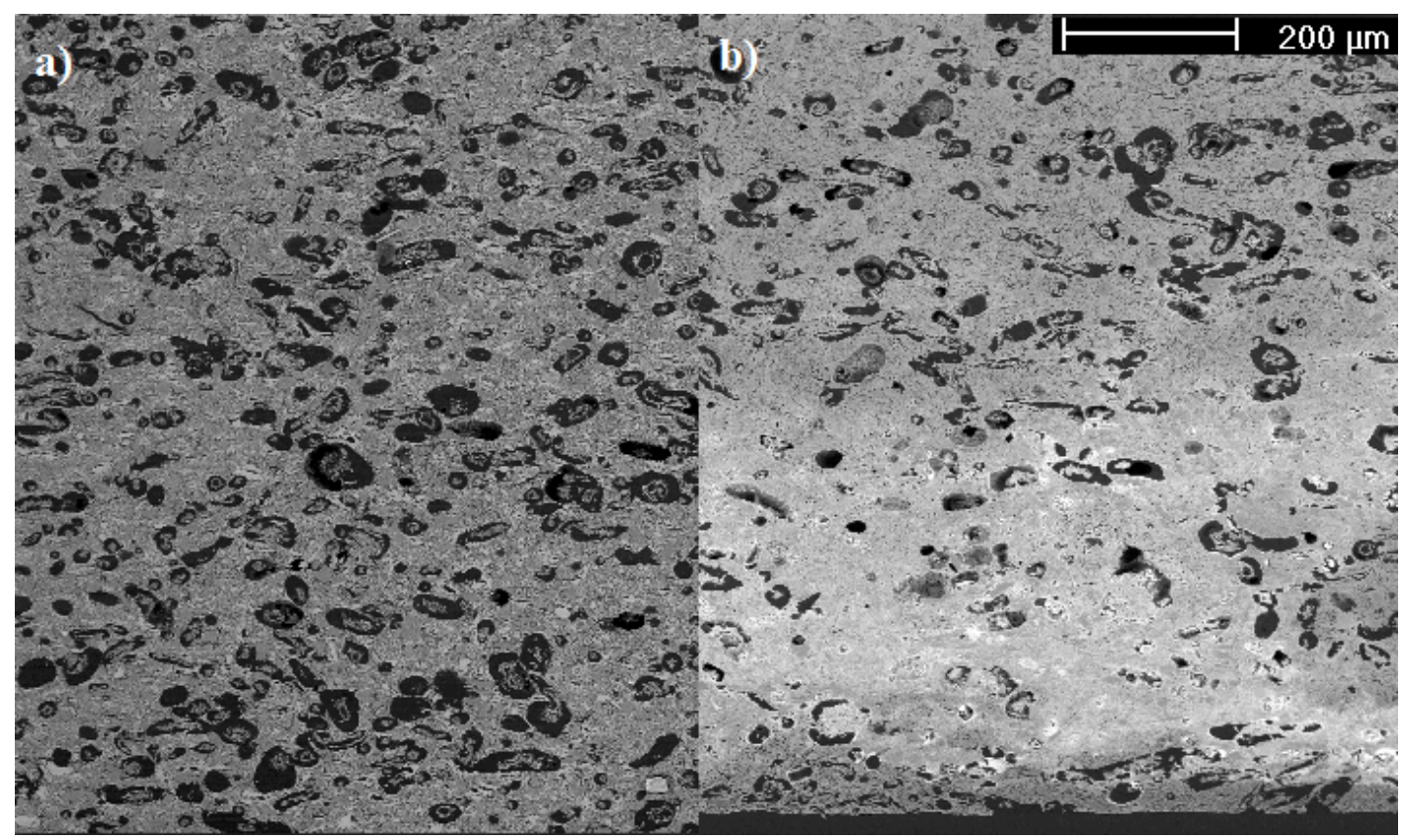

Fig. 3 FEG-SEM images of polished sections. (a) ceramic support obtained from a mixture with $20 \%$ of starch. (b) area near the surface of a membrane obtained from the same support, after five infiltration cycles. 


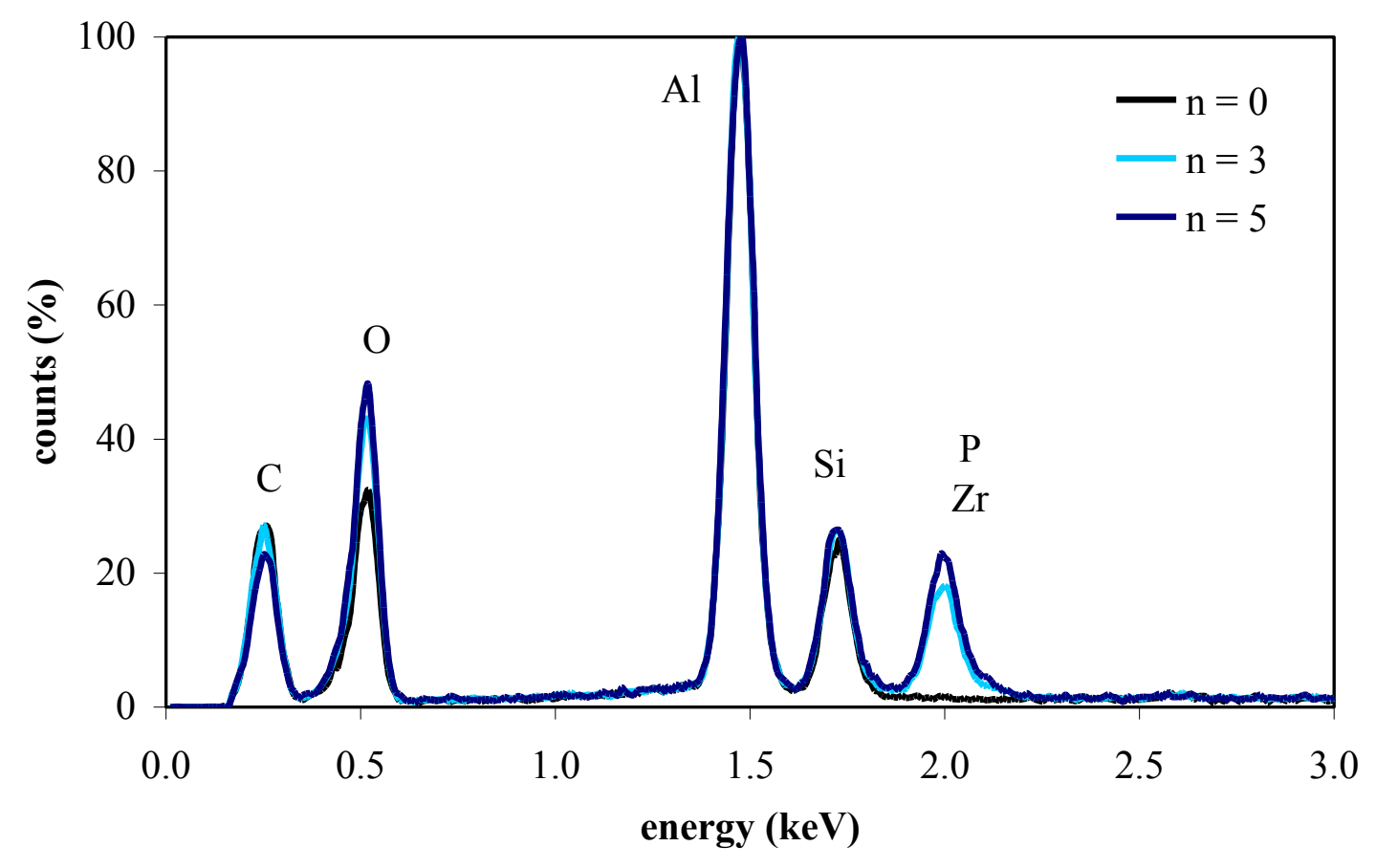

Fig. 4 EDX spectra of the central areas of the support (20\% of starch), and membranes obtained with three and five infiltration cycles. 


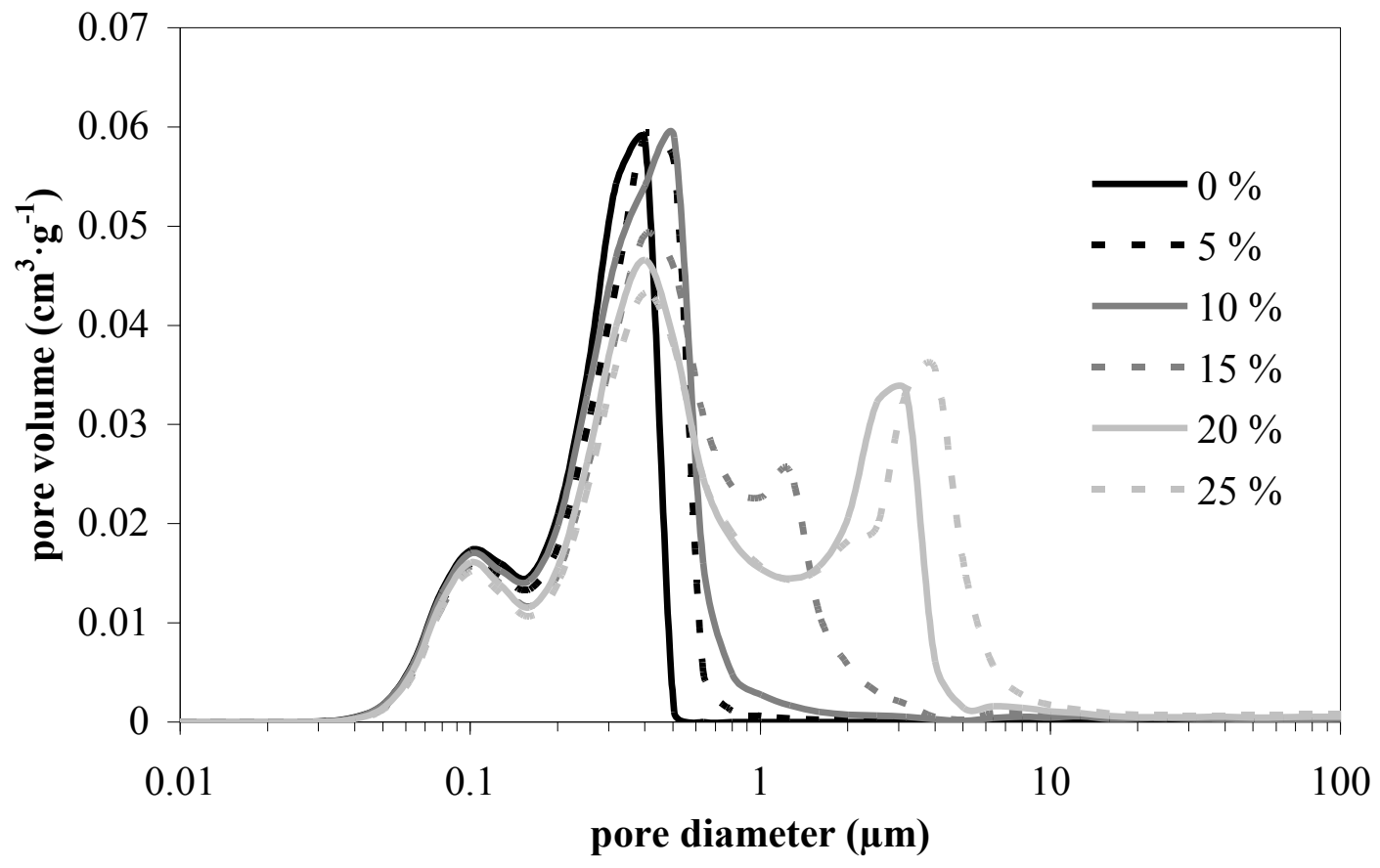

Fig. 5 Differential pore size distributions of the supports obtained from mixtures with different starch contents. 


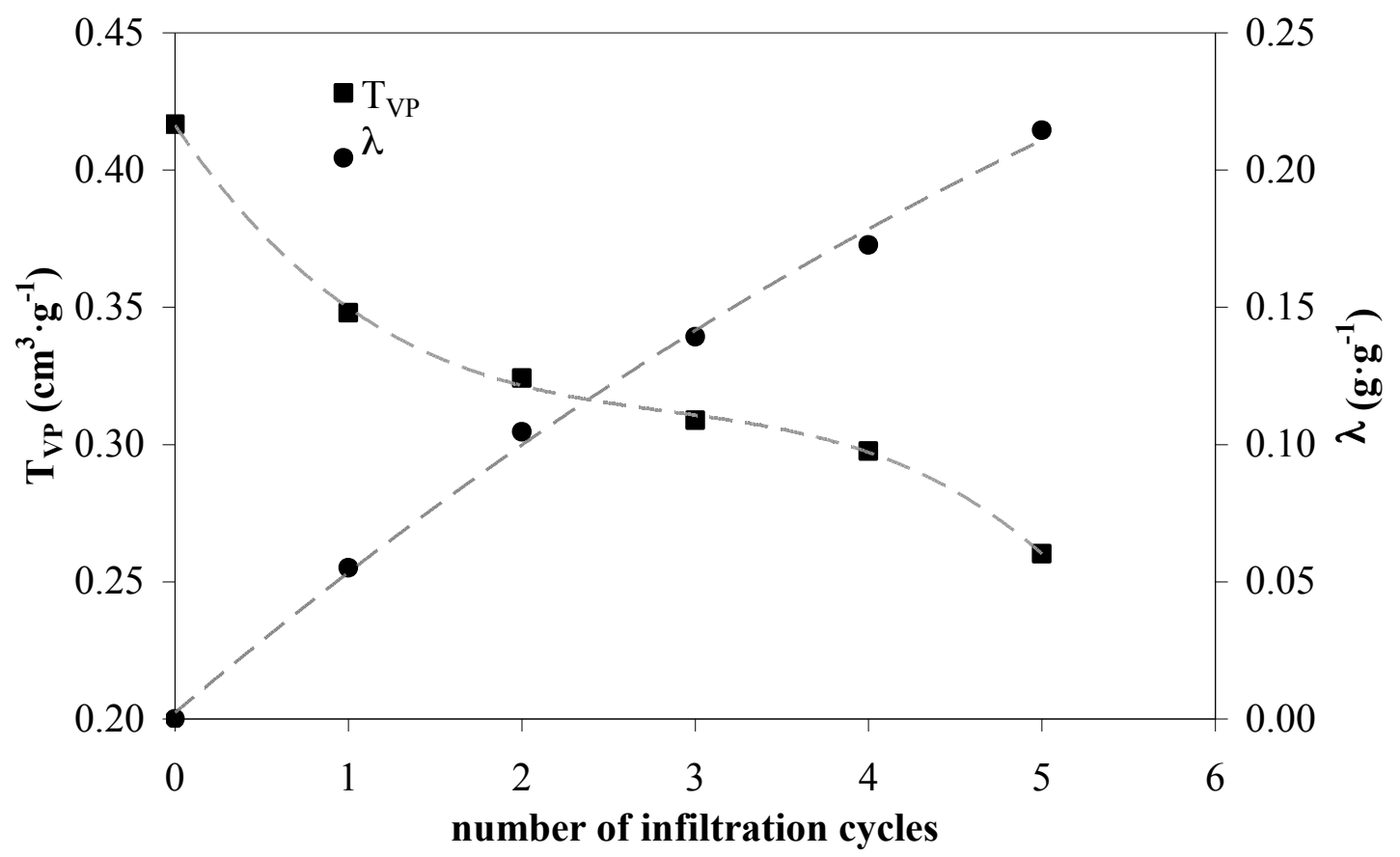

Fig. 6. Effect of the number of infiltration cycles on the total pore volume and $\lambda$ values of the membranes 


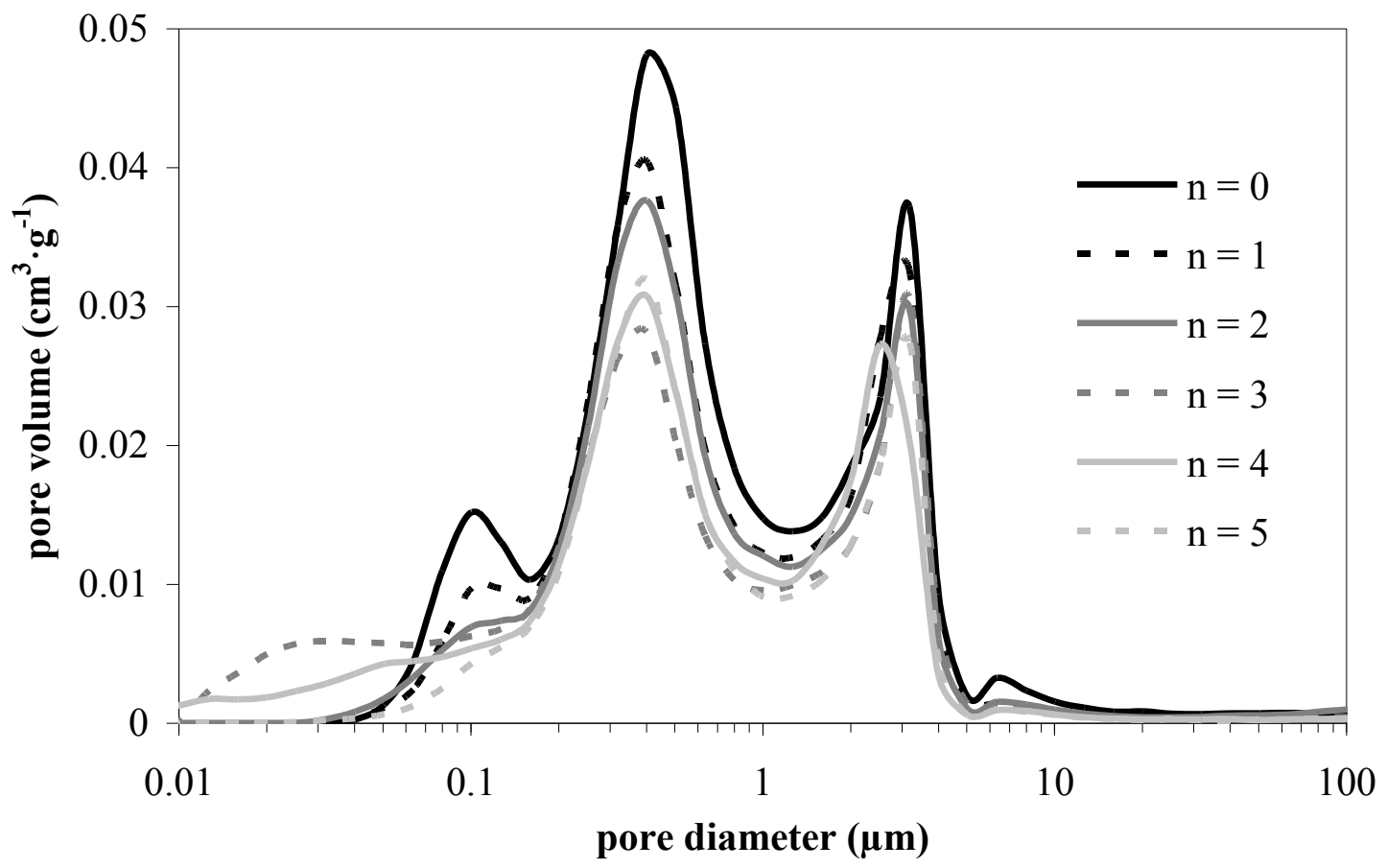

Fig. 7 Effect of the number of impregnation cycles on the differential pore size distribution of the ceramic membranes. 


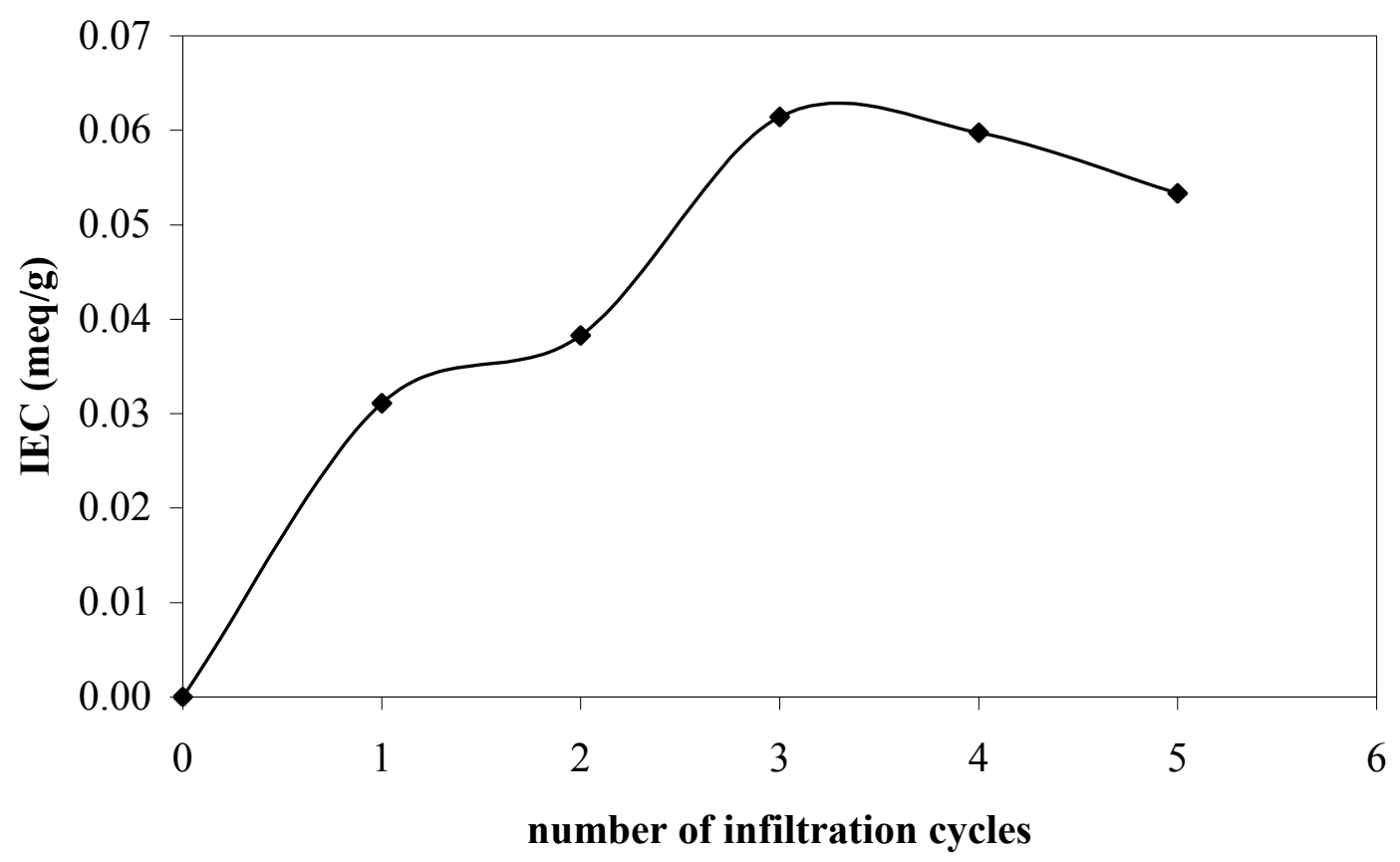

Fig. 8 IEC as a function of the number of impregnation cycles, $n$. 


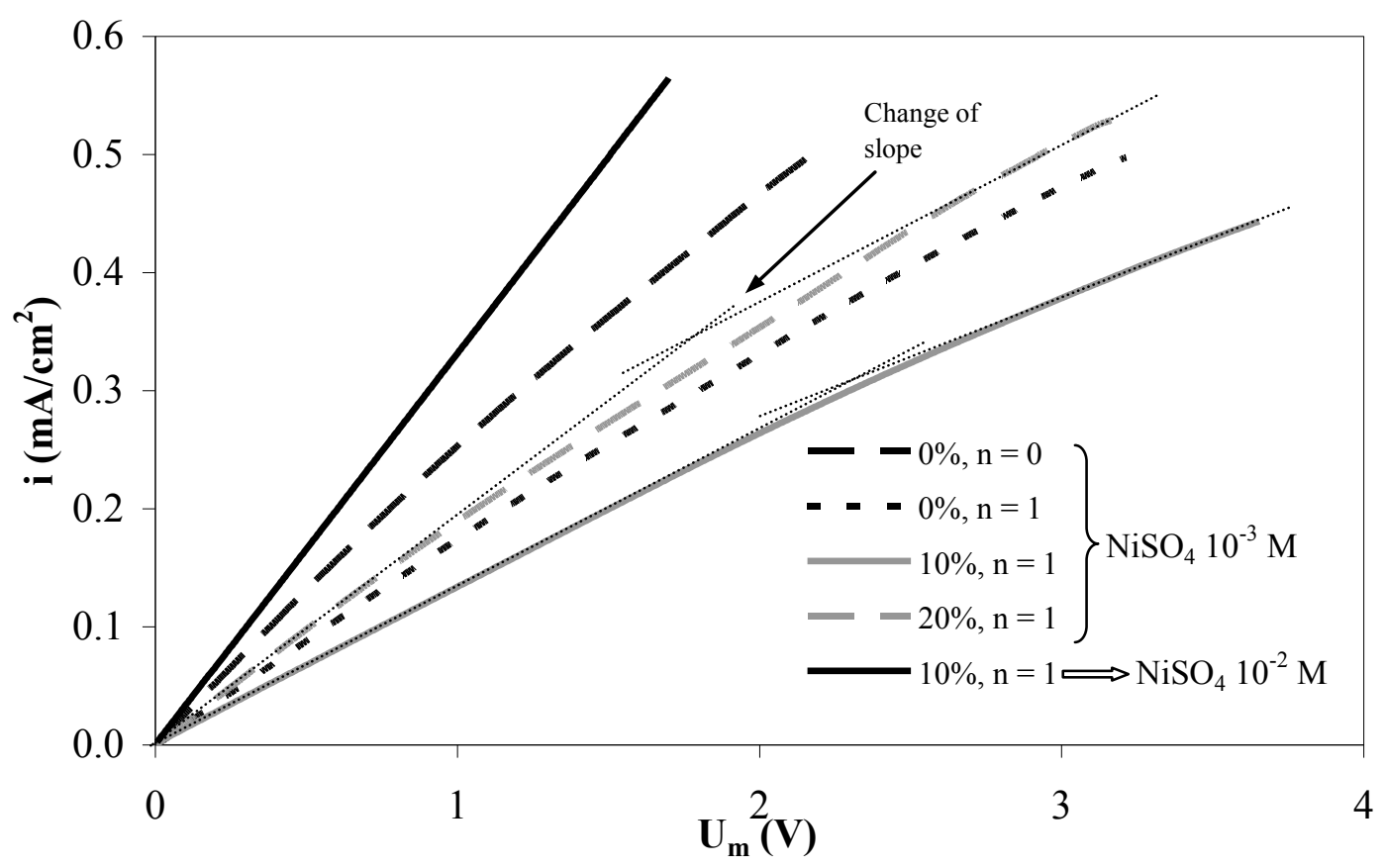

Fig. $9 \mathrm{CVCs}$ obtained for membranes with varying starch contents in $\mathrm{NiSO}_{4}$ solutions. 


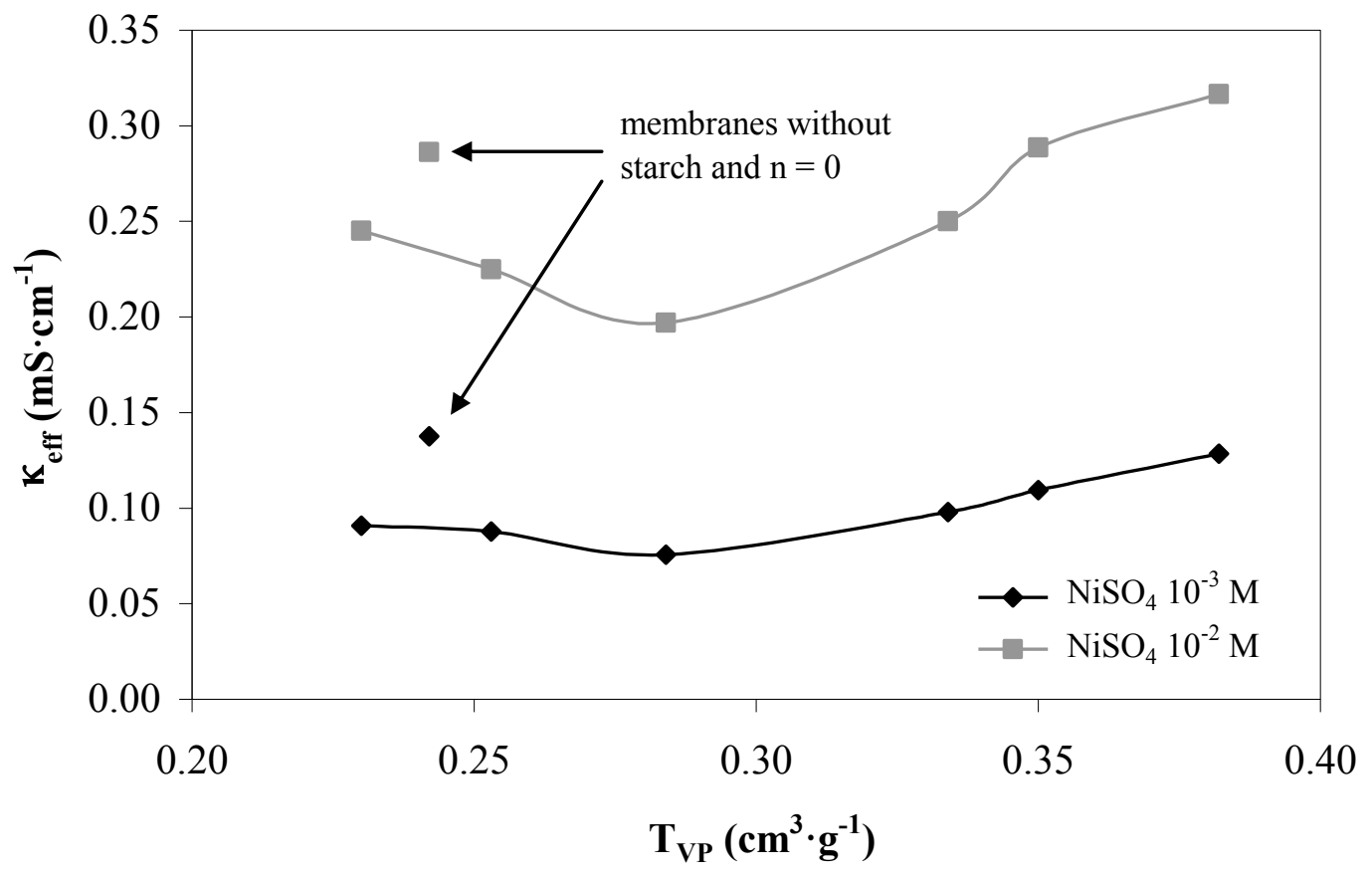

Fig. 10 Values of $\kappa_{\text {eff }}$ for $10^{-3}$ and $10^{-2} \mathrm{M} \mathrm{NiSO}_{4}$ solutions as a function of the total pore volume of the membranes resulting from different starch contents in their fabrication. 


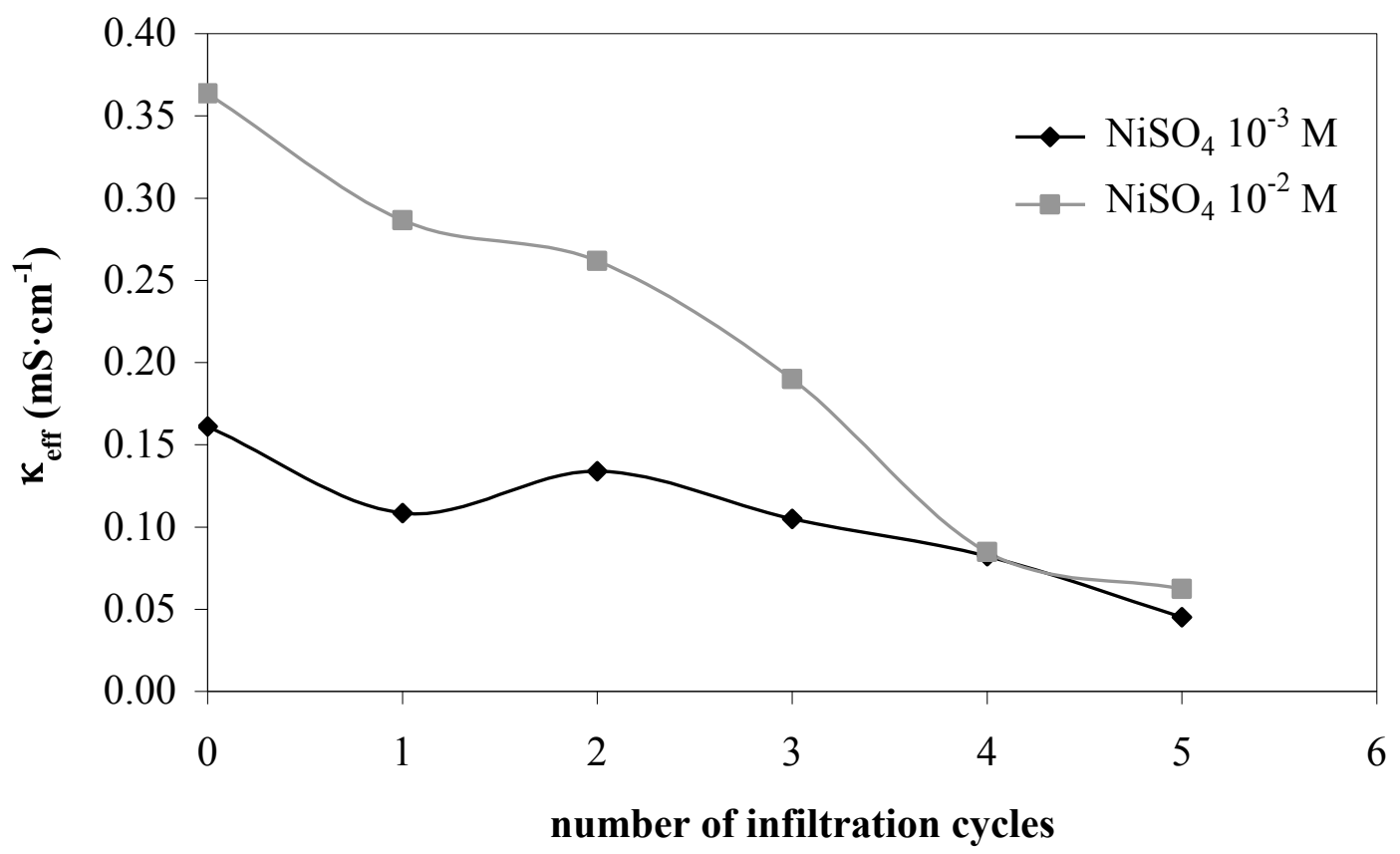

Fig. 11 Values of $\kappa_{\text {eff }}$ for $10^{-3}$ and $10^{-2} \mathrm{M} \mathrm{NiSO}_{4}$ solutions as a function of the number of impregnation steps. 


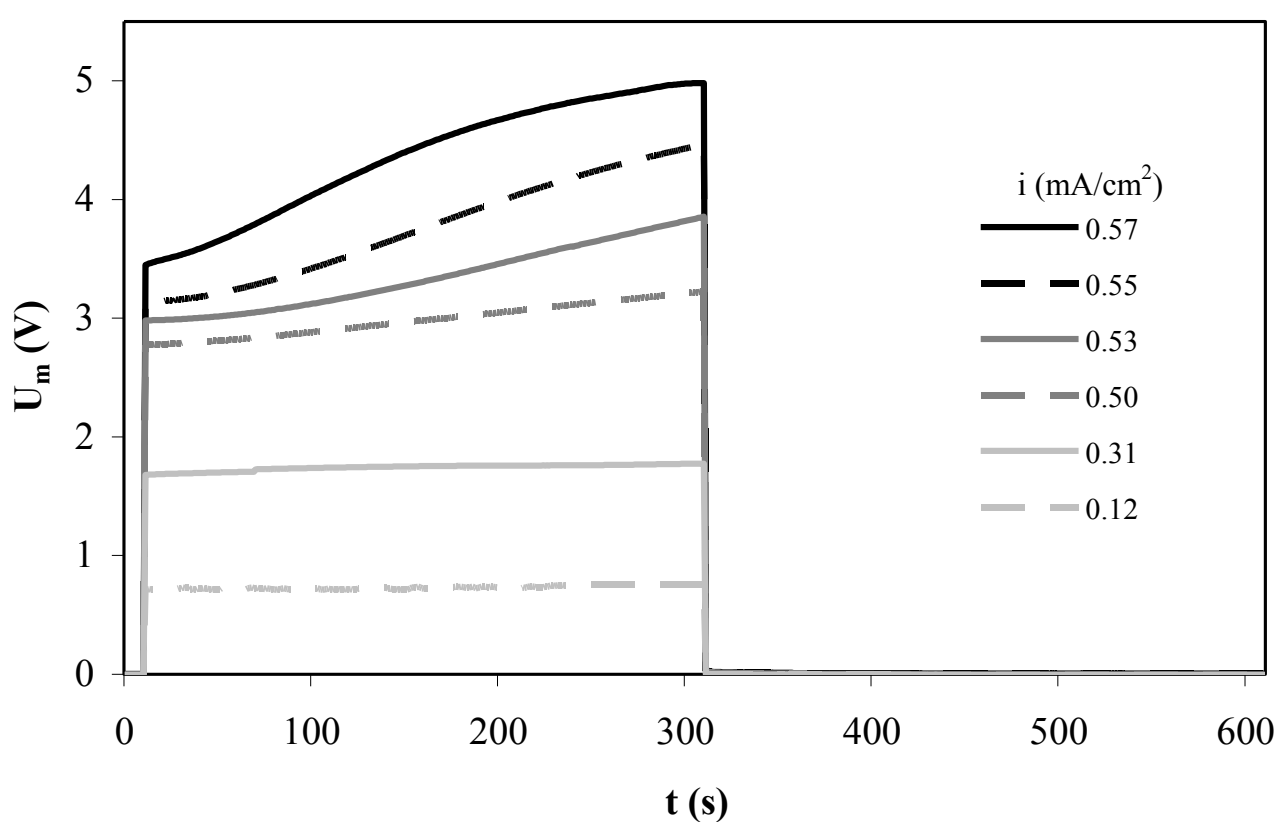

Fig. 12. Chronopotentiometric curves obtained for $10^{-3} \mathrm{M} \mathrm{NiSO}_{4}$ solutions with the CEM resulting from an initial matrix with $20 \%$ starch content and three zirconium phosphate impregnation steps. 


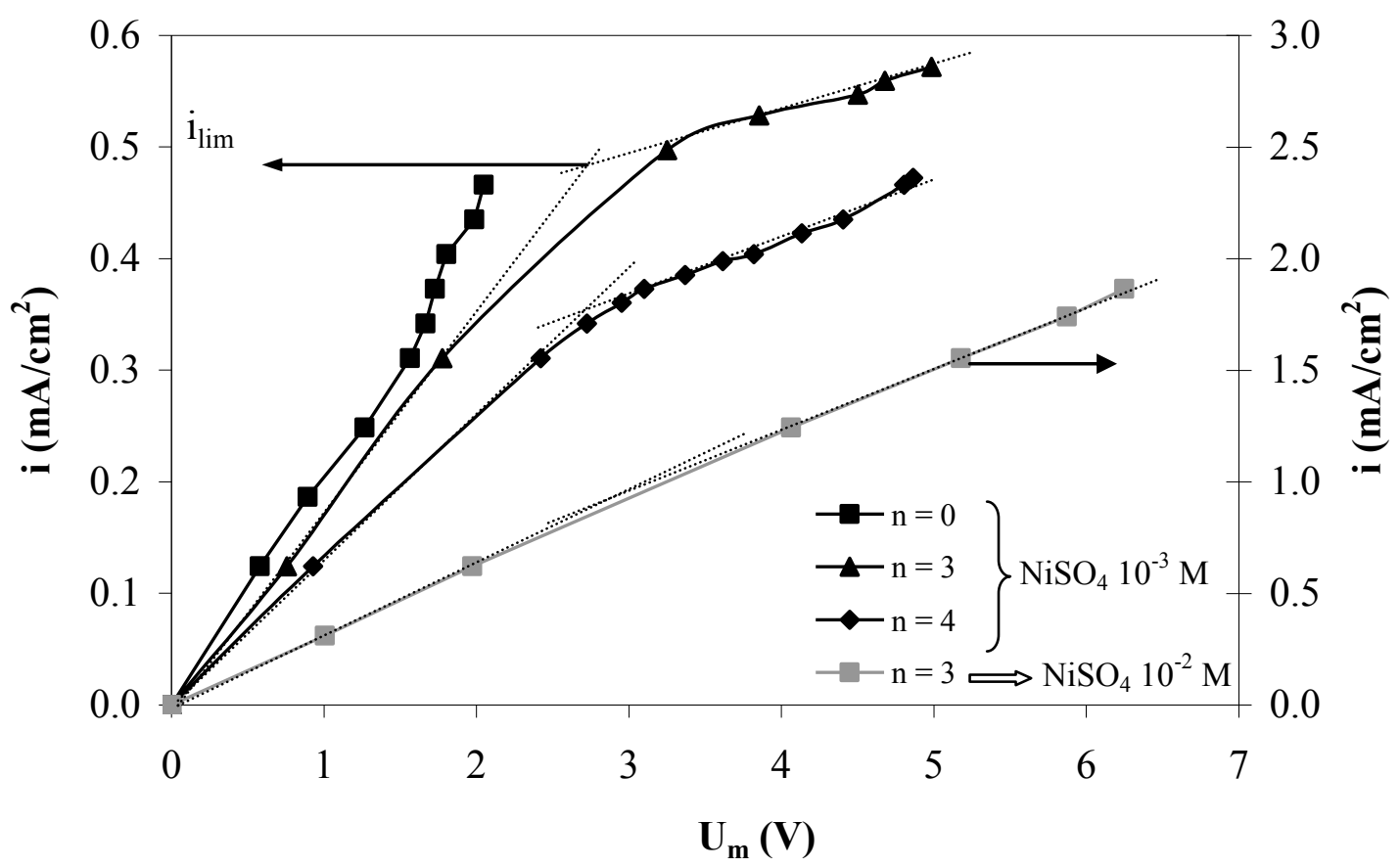

Fig. 13. CVCs obtained from the chronopotentiograms with $10^{-3} \mathrm{M} \mathrm{NiSO}_{4}$ solutions for membranes with varying number of zirconium phosphate impregnation cycles. 